\title{
Anesthetic Technique for Transesophageal Electrophysiology Studies in Pediatric Patients with Wolff-Parkinson-White Syndrome
}

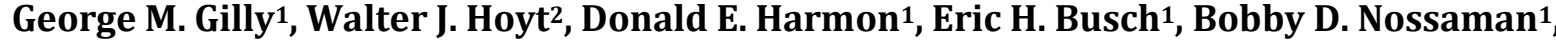 \\ David M. Broussard1, Christopher S. Snyder ${ }^{3 *}$ \\ ${ }^{1}$ Department of Anesthesiology, Ochsner Clinic Foundation, New Orleans, LA, USA \\ ${ }^{2}$ Division of Pediatric Cardiology, University of Virginia, Charlottesville, VA, USA \\ ${ }^{3}$ Department of Pediatrics, Division of Pediatric Cardiology, Rainbow Babies and Children's Hospital, Case \\ Western Reserve School of Medicine, Cleveland, $\mathrm{OH}, \mathrm{USA}$ \\ Email: ${ }^{*}$ Christopher.Snyder@UHhospitals.org
}

Received 28 December 2014; accepted 30 January 2015; published 2 February 2015

Academic Editor: Carl E. Hunt, George Washington University School of Medicine and Health Sciences, USA

Copyright (C) 2015 by authors and Scientific Research Publishing Inc.

This work is licensed under the Creative Commons Attribution International License (CC BY).

http://creativecommons.org/licenses/by/4.0/

c) (i) Open Access

\section{Abstract}

Objective: Patients with Wolff-Parkinson-White (WPW) Syndrome require risk assessment to determine their potential for sudden cardiac death. Transesophageal electrophysiology studies (TEEPS) are an effective risk stratification tool. The purpose of this study is to describe a minimially invasive, effective anesthetic technique to employ during transesophageal electrophysiology studies. Methods: A retrospective review of anesthetic technique utilized during TEEPS. Inclusion criteria; WPW on ECG; age $<18$ years; and no history of tachycardia, palpitations, or syncope and patient had TEEPS under monitored anesthesia care (MAC). Midazolam, Fentanyl, and Propofol were used in various combinations. Sevoflurane was used during induction period in all GA cases and discontinued 10 minutes prior to initiation of TEEPS. Results: Inclusion criteria were met by 20 patients with an average age of 11.9 years, average weight of $48.9 \mathrm{~kg}$ and average height of $149.2 \mathrm{~cm}$. IV sedation was performed on $15 \%$, MAC on $10 \%$ and GA in remainder. Airway management techniques included $13.3 \%$ LMA, 20\% endotrachael tube (ETT) and $66 \%$ mask. IV sedation, the initial anesthetic, was found to be cumbersome and uncomfortable. Next was ETT and LMA but trouble pacing was encountered due to positional change of the esophagus relative to the left atrium during ventilation. Mask induction was then performed in remaining 10 patients with TEEPS probe inserted through a nare while anesthesiologist continued mask ventilation. All mask

\footnotetext{
"Corresponding author.
}

How to cite this paper: Gilly, G.M., Hoyt, W.J., Harmon, D.E., Busch, E.H., Nossaman, B.D., Broussard, D.M. and Snyder, C.S. (2015) Anesthetic Technique for Transesophageal Electrophysiology Studies in Pediatric Patients with Wolff-ParkinsonWhite Syndrome. Open Journal of Pediatrics, 5, 17-22. http://dx.doi.org/10.4236/ojped.2015.51004 
procedures were successful without complications. Conclusions: Induction of anesthesia to perform TEEPS procedures on pediatric patients with Wolff-Parkinson-White syndrome underwent numerous attempts to make the procedure easy, reliable and reproducible for anesthesia and electrophysiologist. The eventual technique that proved to meet these criteria during a transesopheagel electrophysiology procedure was utilization of mask induction with continuous IV sedation.

\section{Keywords}

Wolff Parkinson White, Transesophagel Electrophysiology Study

\section{Introduction}

Wolff-Parkinson-White syndrome (WPW) is an electrocardiographic abnormality that manifests on the electrocardiogram with a short PR interval, presence of a delta wave, and episodes of supraventricular tachycardia [1]. These findings are due to the presence of an accessory pathway (AP) that bridges the electrical activity of the atrium to the ventricles and bypassing the normal conduction delay of the atrio-ventricular node. Many patients with WPW are asymptomatic without complaints of syncope, near-syncope, palpitations, supraventricular tachycardia, atrial fibrillation, or sudden cardiac death (SCD) and are identified only by "routine" electrocardiogram. Regardless, all patients with WPW have risk of SCD due to rapid conduction down their accessory pathway during atrial fibrillation. Due to this risk, current recommendations state that patients with WPW on their ECG undergo formal assessment to determine their risk of SCD. The methods of risk stratification include exercise stress testing, transesophageal electrophysiology studies (TEEPS), and transvenous electrophysiology studies (TVEPS). TVEPS is currently accepted as the most effective way to assess the risk of these patients; however, this procedure is associated with increase cost, time, invasiveness, and risk. In contrast, a TEEPS is easy to perform, less costly, with less risk and excellent success rates [2].

When performing invasive risk assessment on a patient with WPW, the anesthetic plan must be carefully designed to avoid interference with the conduction properties of the accessory pathway (AP) as well as assure a painless and safe procedure for the patient. Traditional anesthetic agents such as Propofol, Fentanyl, and Midazolam have been shown to have negligible effects on the AP conduction [3]-[8]. In contrast to these agents, the volatile anesthetics Sevoflurane and Isoflurane have been shown to increase AP-effective refractory period (AP-ERP), make them conduct better, and therefore it increases the shortest preexcited R-R interval during Afib, potentially taking a patient from no-risk of sudden death into a group that has risk [3] [6] [8] [9]. To date, no safe and effective anesthetic technique has been described for use during the minimally invasive TEEPS procedures. The purpose of this study is to describe our evolution of anesthetic technique to arrive at a safe and effective method of anesthetizing patients for the minimally invasive transesophageal electrophysiology studies during risk assessment of asymptomatic Wolff-Parkinson-White syndrome patients.

\section{Methods}

A retrospective chart review was performed on all patients with asymptomatic WPW that underwent TEEPS procedure at our institution. Inclusion criteria included evidence of preexcitation on ECG (WPW); age < 18 years; and no history of tachycardia, palpitations, or syncope. Data collected included patient age, weight, height, TEEPs results, anesthetic medications and technique(s) utilized. TEEPS studies were performed as part of the risk assessment protocol on asymptomatic WPW patients with the goal of inducing Afib.

Anesthesia was utilized during the study for patient comfort and ease of performing the study. The anesthetic technique evolved during the study as shortfalls were encountered. Initially, the technique was simple IV sedation administered by the performing electrophysiologist. This evolved into the monitored anesthesia care (MAC), or general anesthesia (GA). Each patient had a single anesthesiologist during their case. Anesthetic technique (MAC vs. GA) as well airway management decisions were left to the clinical judgment of the performing anesthesiologist. The anesthetic agents used during the procedure were, Midazolam, Fentanyl, and Propofol alone or in combination. Sevoflurane was also used during the immediate induction period in all GA cases. Airway 
management included mask ventilation, laryngeal mask airway (LMA), or endotracheal intubation [10] [11].

\section{Results}

Inclusion criteria were met by 20 patients with average age of 11.9 years (2 - 17), average weight of $48.9 \mathrm{~kg}$ (13.5 - 104) and average height of $149.2 \mathrm{~cm}$ (89 - 178). The methods of anesthesia included; IV sedation in 3 (15\%), MAC in 2 (10\%), and GA on remaining 15 (75\%). In addition, multiple methods of airway management were employed including Laryngeal Mask Airway (LMA) in 2 (13\%), ETT in 3 (20\%), and pure mask technique in 10 (67\%). The method of anesthesia and airway management had no effect on the final results of the procedure since Afib was induced in 18 of 20 patients. The cases were afib could not be induced were: 1 sedation and 1 GA with LMA.

In the first three cases, IV sedation was utilized but was found to be cumbersome to perform the procedure and uncomfortable for the patient. The issues encountered during its use were difficulty making the patient comfortable and positioning the TEEPS probe without anesthesia. In addition, once the probe was positioned, it required higher thresholds for capture (18 vs. 15 millivolts) with in turn resulted in patient discomfort. Afib was not inducible in one of these patients due to the inability to position the probe in a place where capture of the heart could be reliably obtained. Due to the difficulty of probe placement and sedation, anesthesia was involved in the subsequent patients (17) to anesthetize the patient and allow the electrophysiologist performed the TEEPS.

General anesthesia was performed on next 15 patients. Depending on the age and overall disposition of the patient, IV access was obtained in either the pre-operative suite or after mask induction. In addition, pre-operative Midazolam (IV or PO) was administered to 13 of 15 patients prior to their receiving general anesthesia. Sevoflurane was used to induce general anesthesia on all patients with the highest end tidal recorded of 6 . After induction of general anesthesia and brief maintenance, Sevoflurane was discontinued to avoid any issues with AP conduction. Maintenance of anesthesia was then continued with a combination of IV Propofol and Fentanyl (Table 1). No anesthetic complications were noted.

General anesthetic with endotracheal intubation (GETA) was performed on the first 3 patients that underwent general anesthesia. No anesthetic complications were noted but the electrophysiologist noted difficulty properly positioning the TEEPS probe. The issue positioning the TEEPS probe was felt to be due to a small positional change of the esophagus relative to the left atrium after intubation with a cuffed endotracheal tube and the use of positive pressure ventilation.

For this reason, the anesthesiologist attempted general anesthesia with an LMA for the next 2 patients. Due to the age of the patients (13 and 16 years old), both patients underwent IV induction. Sevoflurane was initially used for maintenance of anesthesia before switching to Propofol, Fentanyl, and Midazolam. No anesthetic complications were noted with this method. As with the previous GETA cases, the TEEPS probe was inserted through the nare; and the LMA was placed and inflated. During both cases, the inflation of the LMA moved the TEEPS probe out of position. Afib was not induced in one patient, so the study was converted to TVEPs with successful induction of Afib.

Due to TEEPS probe positioning problems with the endotracheal tube and the LMA, the subsequent procedures were performed with general mask anesthesia on 10 of 20 patients. Mask induction was performed on 5 of 10 patients with IV placement after induction; the remainder of the patients had IV access placed in the preoperative area. Pre-operative Midazolam and intraoperative Fentanyl were administered to 8 of 10 patients. Two patients received no anxiolytics or narcotics in the pre-operative or intra-operative period. All 10 patients, regardless of IV status, underwent mask induction. The TEEPS probe was inserted through a nare and properly positioned by the electrophysiologist. The anesthesiologist secured the probe in the proper position while continuing to mask ventilate the patient. The procedure was performed and the probe was removed. There were no anesthetic complications in any of these patients.

The remaining 2 patients underwent the TEEPS study under MAC anesthesia which was performed by the pediatric anesthesia team. The patients were 16 and 17 years old and easily tolerated the procedure. Overall, 18 of $20(90 \%)$ patients underwent successful TEEPS studies as defined by induction of A-fib.

\section{Discussion}

WPW can manifest as syncope, near-syncope, palpitations, supraventricular tachycardia, atrial fibrillation, or 
Table 1. Demographics and anesthetic techniques in twenty patients undergoing TEEPs.

\begin{tabular}{|c|c|c|c|c|c|c|c|c|c|c|}
\hline Age & $\begin{array}{c}\text { Weight } \\
\text { (kg) }\end{array}$ & $\begin{array}{c}\text { Height } \\
\text { (cm) }\end{array}$ & Anesthesia & Airway & $\begin{array}{l}\text { Sevoflurane } \\
\text { Max (\%) }\end{array}$ & Narcotics & $\begin{array}{c}\text { Pre-Op } \\
\text { Midazolam }\end{array}$ & $\begin{array}{c}\text { Intra-Op } \\
\text { Midazolam }\end{array}$ & $\begin{array}{c}\text { Propofol } \\
\text { (mg) }\end{array}$ & $\begin{array}{c}\text { Neuromuscular } \\
\text { Blocker }\end{array}$ \\
\hline 5 & 25.9 & 94 & General & Mask & 1.4 & 0 & $5 \mathrm{mg}$ PO & 0 & 0 & 0 \\
\hline 9 & 32.5 & 135 & IV Sedation & NC & 0 & Fentanyl $70 \mathrm{mcg}$ & 15 mg PO & $2 \mathrm{mg}$ IV & 60 & 0 \\
\hline 16 & 48 & 163 & IV Sedation & $\mathrm{NC}$ & 0 & 0 & 0 & 0 & 170 & 0 \\
\hline 17 & 63 & 170 & IV Sedation & NC & 0 & 0 & 0 & $6 \mathrm{mg}$ IV & 190 & 0 \\
\hline 17 & 72 & 178 & General & ETT & 3.9 & Fentanyl 125 mcg & $2 \mathrm{mg}$ IV & 0 & 200 & Succinylcholine $100 \mathrm{mg}$ \\
\hline 13 & 47 & 161 & General & Mask & 3.5 & Fentanyl $100 \mathrm{mcg}$ & 0 & 0 & 0 & 0 \\
\hline 13 & 62 & 160 & General & Mask & 2 & Fentanyl $100 \mathrm{mcg}$ & $2 \mathrm{mg}$ IV & 0 & 0 & 0 \\
\hline 15 & 72.3 & 179 & General & ETT & 2 & Fentanyl $100 \mathrm{mcg}$ & $2 \mathrm{mg}$ IV & 0 & 0 & Rocuronium 30 mg \\
\hline 13 & 58 & 169 & General & LMA & 6 & Fentanyl $100 \mathrm{mcg}$ & 0 & $2 \mathrm{mg}$ IV & 200 & 0 \\
\hline 16 & 53.8 & 172 & General & LMA & 2 & Fentanyl $50 \mathrm{mcg}$ & 0 & $2 \mathrm{mg}$ IV & 150 & 0 \\
\hline 11 & 45.1 & 147 & General & Mask & 2 & Fentanyl 50 mcg & 20 mg PO & 0 & 200 & 0 \\
\hline 17 & 104 & 173 & General & Mask & & Fentanyl 200 mcg & $2 \mathrm{mg}$ IV & 0 & 0 & 0 \\
\hline 9 & 34.6 & 146 & General & Mask & 3 & 0 & 0 & 0 & 0 & 0 \\
\hline 16 & 64.1 & 156 & MAC & MAC & 0 & Fentanyl $100 \mathrm{mcg}$ & $2 \mathrm{mg}$ IV & 0 & 140 & 0 \\
\hline 2 & 13.5 & 89 & General & Mask & 6 & 0 & 7 mg PO & 0 & 0 & 0 \\
\hline 17 & 62.3 & 180 & MAC & MAC & 0 & Fentanyl $50 \mathrm{mcg}$ & $2 \mathrm{mg}$ IV & $1 \mathrm{mg}$ IV & 200 & 0 \\
\hline 9 & 28 & 132 & General & ETT & 4 & Fentanyl 50 mcg & 15 mg PO & 0 & 80 & Rocuronium 25 mg \\
\hline 5 & 24 & 115.5 & General & Mask & 4 & 0 & 12 mg PO & 0 & 0 & 0 \\
\hline 11 & 50 & 149 & General & Mask & 6 & 0 & $2 \mathrm{mg}$ IV & 0 & 90 & 0 \\
\hline 6 & 18.6 & 115 & General & Mask & 1.8 & 0 & $10 \mathrm{mg}$ PO & 0 & 0 & 0 \\
\hline
\end{tabular}

MAC: Monitored Anesthesia Care; ETT: Endotracheal Tube; NC: Nasal Canula.

even sudden cardiac death which necessitates risk stratification of asymptomatic patients. Current procedures of risk stratification include exercise stress testing, transesophageal electrophysiology studies (TEEPS), and transvenous electrophysiology studies (TVEPS). Exercise stress testing is a non-invasive test used to rule out asymptomatic ventricular preexcitation (aVPE) but is limited by its sensitivity in patients with WPW. TVEPS is an effective way to risk stratify patients; however, it is hampered by its invasiveness, cost, and potential complica- 
tions. TEEPS procedures have been shown to be an effective screening tool with potentially less complications; however no consensus anesthetic technique has been proven superior [2]. This study series describes our attempt to find the easiest, most effective anesthetic technique for the TEEPS procedure.

Depending on the age and co-existing diseases of the patient, this procedure can successfully be performed under MAC or GA. In the older pediatric population, MAC is likely the preferred anesthetic technique due to minimal airway manipulation, the ability to bypass phase I recovery, decreased risk of post-operative nausea and vomiting (PONV). If a patient is unable to tolerate MAC, conversion to GA only requires deepening of IV sedation and airway management by mask ventilation. As shown by our case series, pediatric patients who undergo mask induction for the purpose of obtaining IV access tolerate general anesthesia with mask ventilation for maintenance. The advantages of this technique are that the patient's oropharynx is unobstructed for TEEPS probe placement and when necessary the probe can be easily manipulated by the anesthesiologist during the procedure. In our study, TEEPS probe adjustment was more difficult with an ETT or LMA in place.

Techniques such as MAC or mask general that minimize airway manipulation likely decrease the risk of laryngospasm during TEEPS procedure. Laryngospasm did not occur in any patient in this series, regardless of the technique employed. Probe placement should be performed only after IV access is obtained, and the patient is adequately anesthetized to minimize this risk. The results of this case series suggest that MAC or mask general anesthesia is the preferred anesthetic technique for the TEEPS procedure.

\section{Conclusion}

Induction of anesthesia to perform TEEPS procedures on pediatric patients with Wolff-Parkinson-White syndrome underwent numerous attempts to make the procedure easy, reliable and reproducible for anesthesia and electrophysiologist. The eventual technique that proved to meet these criteria during a transesopheagel electrophysiology procedure was utilization of mask induction with continuous IV sedation.

\section{References}

[1] Wolff, L., Parkinson, J. and White, P.D. (1930) Bundle Branch Block with Short PR Interval in Healthy Young People Prone to Paroxysmal Tachycardia. American Heart Journal, 5, 686-692. http://dx.doi.org/10.1016/S0002-8703(30)90086-5

[2] Hoyt, W.J., Thomas, P.E., DeSena, H.C., Steinberg, J.S., Harmon, D.E. and Snyder, C.S. (2012) Atrial Fibrillation Induction by Transesophageal Electrophysiology Studies in Patients with Asymptomatic Ventricular Preexcitation. Congenital Heart Disease, 8, 57-61.

[3] Lavoie, J., Walsh, E.P., Burrows, F.A., Laussen, P., Lulu, J.A. and Hansen, D.D. (1995) Effects of Propofol or Isoflurane Anesthesia on Cardiac Conduction in Children Undergoing Radiofrequency Catheter Ablation for Tachydysrhythmias. Anesthesiology, 82, 884-887. http://dx.doi.org/10.1097/00000542-199504000-00010

[4] Sharpe, M.D., Dobkowski, W.B., Murkin, J.M., Klein, G. and Yee, R. (1995) Propofol Has No Direct Effect on Sinoatrial Node Function or on Normal Atrioventricular and Accessory Pathway Conduction in Wolff-Parkinson-White Syndrome during Alfentanil/Midazolam Anesthesia. Anesthesiology, 82, 888-895. http://dx.doi.org/10.1097/00000542-199504000-00011

[5] Sharpe, M.D., Dobkowski, W.B., Murkin, J.M., Klein, G., Guiraudon, G. and Yee, R. (1992) Alfentanil-Midazolam Anaesthesia Has No Electrophysiological Effects upon the Normal Conduction System or Accessory Pathways in Patients with Wolff-Parkinson-White Syndrome. Canadian Journal of Anaesthesia, 39, 816-821. http://dx.doi.org/10.1007/BF03008294

[6] Sharpe, M.D., Dobkowski, W.B., Murkin, J.M., Klein, G., Guiraudon, G. and Yee, R. (1994) The Electrophysiologic Effects of Volatile Anesthetics and Sufentanil on the Normal Atrioventricular Conduction System and Accessory Pathways in Wolff-Parkinson-White Syndrome. Anesthesiology, 80, 63-70. http://dx.doi.org/10.1097/00000542-199401000-00013

[7] Pecht, B., Maginot, K.R., Boramanand, N.K. and Perry, J.C. (2002) Techniques to Avoid Atrioventricular Block during Radiofrequency Catheter Ablation of Septal Tachycardia Substrates in Young Patients. Journal of Interventional Cardiac Electrophysiology, 7, 83-88. http://dx.doi.org/10.1023/A:1020828401929

[8] Pérez, E.R., Bartolomé, F.B., Carretero, P.S., Fernández, C.S., Mateos, E.J. and Tarlovsky, L.G. (2008) Electrophysiological Effects of Sevoflurane in Comparison with Propofol in Children with Wolff-Parkinson-White Syndrome. Rev Esp Anestesiol Reanim, 55, 26-31.

[9] Caldwell, J.C., Fong, C. and Muhyaldeen, S.A. (2010) Should Sevoflurane Be Used in the Electrophysiology Assess- 
ment of Accessory Pathways? Europace, 12, 1332-1335. http://dx.doi.org/10.1093/europace/euq076

[10] Klein, G.J., Bashore, T.M., Sellers, T.D., Pritchett, E.L., Smith, W.M. and Gallagher, J.J. (1979) Ventricular Fibrillation in the Wolff-Parkinson-White Syndrome. The New England Journal of Medicine, 301, 1080-1085. http://dx.doi.org/10.1056/NEJM197911153012003

[11] Bromberg, B.I., Lindsay, B.D., Cain, M.E. and Cox, J.L. (1996) Impact of Clinical History and Electrophysiologic Characterization of Accessory Pathways on Management Strategies to Reduce Sudden Death among Children with Wolff-Parkinson-White Syndrome. Journal of the American College of Cardiology, 27, 690-695.

http://dx.doi.org/10.1016/0735-1097(95)00519-6 
Scientific Research Publishing (SCIRP) is one of the largest Open Access journal publishers. It is currently publishing more than 200 open access, online, peer-reviewed journals covering a wide range of academic disciplines. SCIRP serves the worldwide academic communities and contributes to the progress and application of science with its publication.

Other selected journals from SCIRP are listed as below. Submit your manuscript to us via either submit@scirp.org or Online Submission Portal.
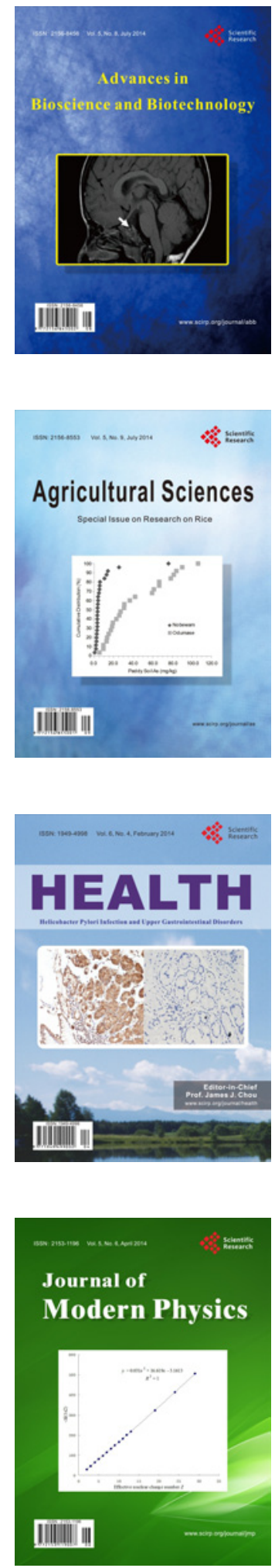
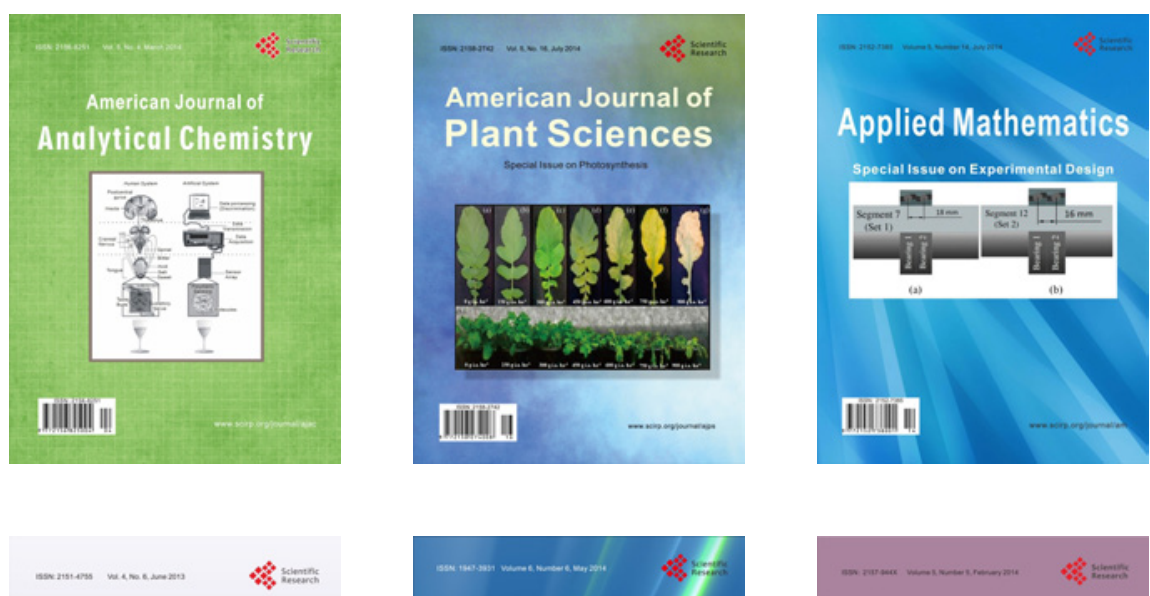

Creative Education
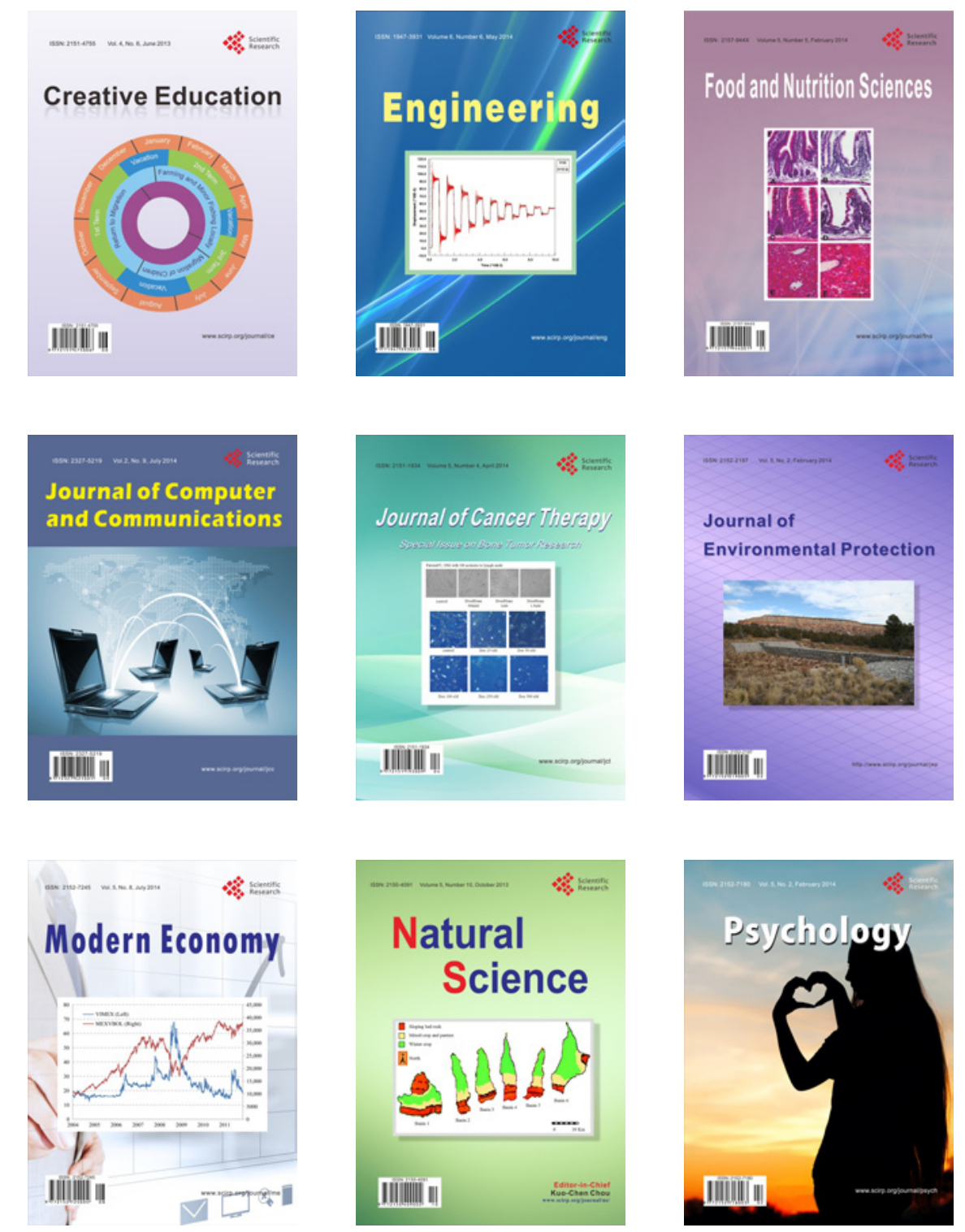